\title{
EDUCAÇÃO FÍSICA NOS ANOS INICIAIS DO ENSINO FUNDAMENTAL: A QUESTÃO DA UNIDOCÊNCIA
}

DOI: $105902 / 010283089050$

Data de submissão: 27/05/2013 Data de Aceite: 22/05/2014

\author{
Denise Grosso da Fonseca \\ Universidade Federal do Rio Grande do Sul \\ dgf.ez@terra.com.br \\ Lisiane Torres e Cardoso \\ Universidade Federal do Rio Grande do Sul \\ lisiane.torres@ufrgs.br
}

RESUMO: Este artigo é um recorte da pesquisa intitulada "Políticas de formação de professores: quais suas implicações na prática Pedagógica da educação física em escolas Públicas estaduais?" Tem como objetivo refletir sobre a educação física nos anos iniciais enfocando a unidocência como prática pedagógica e gratificação salarial. É uma investigação de natureza qualitativa, realizada através de análise documental e entrevista semi-estruturada com seis professores. Em que pese a argumentação pedagógica e legislativa que justifica a unidocência, a análise das informações aponta que, no tocante à Educação Física, sua prática precisa ser revista.

Palavras chave: Prática pedagógica. Educação Física. Unidocência 


\section{Introduzindo o Tema}

A Educação Física é uma área de conhecimento que há muito tempo faz parte do cenário escolar brasileiro. A partir da promulgação da LDB/1996, inúmeros documentos têm fixado diretrizes e orientado a organização da Educação Física na Educação Básica. Os Parâmetros Curriculares Nacionais (PCN, 1997) foram publicados com o intuito de ampliar e aprofundar o debate educacional, procurando respeitar a diversidade e considerar as necessidades regionais para a construção de referenciais nacionais ao processo educativo.

Tratando mais especificamente dos anos iniciais do Ensino Fundamental, o documento destaca que além das inúmeras possibilidades atitudinais e conceituais presentes nas situações educativas, o desenvolvimento de habilidades motoras, a vivência de experiências da cultura corporal, ricas e diversificadas, devem ser o foco principal do trabalho da Educação Física.

Dentre inúmeras questões relacionadas à Educação Física escolar que instigam nossas reflexões, a prática deste componente nos anos iniciais e sua relação com a unidocência tem nos desafiado a (re)tomar o tema como foco de análise. Neste trabalho pretendemos (re)discutir tal questão tomando como base as entrevistas realizadas com professores de uma escola pública estadual na cidade de Porto Alegre, RS. Trata-se de uma investigação de natureza qualitativa, realizada através de análise documental (publicações e documentos legais relativos à unidocência), e entrevista semi-estruturada individual, com quatro professoras unidocentes e os dois professores de educação física da escola. As professoras escolhidas eram responsáveis respectivamente, por turmas do primeiro ao quarto ano e foram indicadas pela supervisão da escola. A finalidade do estudo foi compreender as visões dos interlocutores sobre prática pedagógica da educação física nos anos iniciais do ensino fundamental.

Apesar de importantes estudos relativos à temática da Educação Física nos anos iniciais do ensino fundamental (SILVA e KRUG, 2008; MENSCH e SCHUENGLER, 2009; CONTREIRA e KRUG, 2010; SCHÜTZ, 2011;CRUZ e NETO, 2012), o contato com a realidade escolar, vivenciado pelas autoras deste artigo, indica que ainda há o que se discutir sobre a relação entre a educação física e unidocência, sendo o que passaremos a discutir, iniciando pelos aspectos relativos à organização do ensino nos anos iniciais e à legislação sobre a unidocência. 


\section{A Organização do Ensino nos Anos Iniciais}

O Parecer 853/1971, descreve os pressupostos que embasaram a organização curricular do Ensino de $1^{\circ} \mathrm{Grau}$, atual Ensino Fundamental, em: Currículo por atividades, Áreas de estudos e Disciplinas, destacando que as séries iniciais, serão tratadas predominantemente como atividades.

De acordo com Oliveira (1988), o currículo por atividades se sustenta nas ideias de que o ensino deve ser globalizado, deve ter o aluno como centro do processo e deve ser desenvolvido através de atividades apoiadas no princípio do aprender fazendo. Destaca que "nesta fase a criança tem mais facilidade de perceber o todo, ela tem uma percepção global da realidade, uma percepção sincrética, para só após iniciar o processo de análise (OLIVEIRA, 1988, p.70). Assim, para a autora, tais argumentos justificam que um único professor atenda a todas as situações de aprendizagem e procure integrar as matérias de ensino, podendo receber assessoramento de especialistas.

Entendemos que as ideias precursoras do currículo por atividades e, em boa parte justificadoras da unidocência não são recentes. Pedagogos da Escola Nova ${ }^{1}$ destacam o caráter sincrético do processo de aprendizagem infantil que ocorre de forma global. Baseados nisso, autores da época ${ }^{2}$ procuravam explicar a forma como deveria ser tratado o ensino para atender a essa característica de totalidade.

Não se deve confundir a globalização com a correlação dos estudos. A correlação enlaça as matérias de ensino de modo que fiquem em estreita e íntima relação,[...]; mas, ao mesmo tempo conserva a separação das disciplinas.[...]A globalização prescinde dessas distribuições e considera cada aspecto da aprendizagem como parte de uma matéria única.(AGUAYO, 1947, p. 53)

Para o autor, não se trata de buscar uma integração entre as disciplinas, ou uma interdisciplinaridade, pois para ele não há configuração de disciplinas, mas de conhecimentos que devem ser estudados ou aprendidos de uma forma peculiar, global, de acordo com a capacidade ou com as características do momento de desenvolvimento da criança. "Toma o nome de globalização do ensino essa supressão das demarcações entre disciplinas escolares" (AGUAYO, 1947, p.53).

\footnotetext{
${ }^{1}$ Movimento de renovação da educação surgido nas décadas de 1920 e 1930 que, orientado pelos estudos da psicologia, da medicina neurológica e da biologia, passa a reconhecer que a criança não é um adulto em miniatura e se propõe a romper com o modelo racionalista da escola tradicional, através de métodos ativos. ${ }^{2}$ Referência feita à obra citada neste estudo, publicada no Brasil no ano de 1947, onde é discutida a concepção de globalização a partir dos autores que influenciaram a pedagogia da Escola Nova.
} 
Retomando os pressupostos do currículo por atividades, na perspectiva de fazermos uma releitura à luz de discussões atuais, a questão da globalização aparece nos debates acerca do ensino nos anos iniciais quando são abordadas práticas inovadoras e dentre elas a Pedagogia de Projetos. A busca da superação de modelos tradicionais de ensino, organizados através da listagem de conteúdos a serem vencidos por etapas, segundo Barbosa (2000), percorreu um longo trajeto desde as propostas de Centros de Interesse de Decroly e Metodologia de Projetos de Dewey preconizadas na Escola Nova, sendo ressignificadas através do uso de Eixos Temáticos, Temas Geradores e Pedagogia de Projetos.

Passados mais de meio século voltamos a falar de projetos, mas isso não significa retomá-los do mesmo modo como a Escola Nova os propunha, mas ressignificálos dando-lhes uma nova face que inclua o contexto sócio-histórico e não apenas o ambiente imediato das crianças.( BARBOSA, 2000, p.80)

Quase parafraseando a autora, passados 40 anos que o currículo dos anos iniciais passou a ser caracterizado na forma de atividades, com a presença de um único professor, perguntamos: como está a prática da Educação Física? O que temos, nestas últimas quatro décadas, quando se trata de Educação Física nesse nível de escolaridade nas escolas públicas estaduais?

É importante ressaltar que no Parecer 853/1971, em relação ao escalonamento proposto para a abordagem do conhecimento da maior para a menor amplitude favorecendo uma transição do menos para o mais específico, há referência à presença de um único professor nos anos iniciais aumentando-se o número de docentes nos anos finais. Entretanto o texto traz uma ressalva: "É de supor que ainda se tenham mestres a parte somente para Educação Física e Educação Artística [...]"( Parecer 853/1971, p.187).

Chama nossa atenção que a legislação apresenta aspectos pedagógicos que caracterizam o currículo por atividades os quais são referência também para o exercício da unidocência, mas coloca, paralelamente, a possibilidade da presença de professor especializado para os componentes Educação Artística e Educação Física.

Sayão (1999) comenta que a presença do professor "especialista" (grifo da autora) em determinada disciplina, na organização curricular, já determina uma concepção fragmentária de conhecimento. 
Já Ayoub (2001) afirma ser possível que profissionais de diferentes áreas trabalhem em parceria na educação infantil. Para esta autora mudanças excessivas de professores e/ou de atividades no mesmo dia podem dificultar as relações educativas. Argumento que cabe para os anos iniciais do ensino fundamental, tendo em vista que os pressupostos que sustentam a concepção de um único professor são os mesmos: vínculos afetivos e características dos processos de aprendizagem das crianças pequenas.

Ainda Ayoub (Op cit) reforça a construção de relações de parceria e não hierarquizadas entre profissionais levando a pensar não mais em professores generalistas e especialistas, mas em docentes que juntos compartilhariam seus saberes na construção de projetos educativos.

Fraga (2005) destaca a importância de pensar a educação física não apenas a partir da questão da presença/ausência do professor da área ministrando aulas para crianças nos anos iniciais, o que poderia fazer com que a questão se centrasse numa disputa corporativa. Conforme o autor há diferentes formas de se incluir e valorizar a educação física nesse contexto, como, por exemplo, inserir professores desta área "sob forma de assessoria, atuando na elaboração de planejamentos e oferecendo subsídios teórico-metodológicos para lidar com a relação de ensino-aprendizagem através das práticas corporais, perspectiva também defendida por boa parte dos professores/as unidocentes" (FRAGA, 2005, p. 2).

Nesta perspectiva, Darido (2001) relata projeto desenvolvido em escola pública através de um trabalho conjunto entre professoras de sala e estagiários do curso de licenciatura em educação física, fazendo com que elas observassem as aulas e auxiliassem quando necessário. Porém, na maioria das vezes as professoras se afastavam, comprometendo a proposta do projeto e, de certa forma, levando a crer que não davam a devida importância ao vínculo que precisaria ser mantido.

Como é possível verificar, diferentes alternativas tem buscado superar os descompassos identificados nas aulas de educação física dos anos iniciais do ensino fundamental ministradas por professor unidocente. Para ampliar e aprofundar o debate passaremos a analisar documentos legislativos, em nível nacional e estadual que tem colocado em pauta essa questão. 


\title{
A Dimensão Político-Legislativa
}

O Parecer CNE 16/2001 trata de consulta sobre a obrigatoriedade da Educação Física como componente curricular da Educação Básica e da exigibilidade da formação específica em Educação Física para os quatro primeiros anos do Ensino Fundamental. Com relação a este aspecto, sugere que a prática multidisciplinar, entendida como um único professor ministrando os diferentes componentes deve ser mantida, pois está respaldada na legislação atual. Complementa o argumento, fazendo as seguintes considerações:

Nos quatro primeiros anos do ensino fundamental, a prática multidisciplinar é amplamente disseminada entre nós. A Matemática não é ensinada por matemático, a Língua Portuguesa não é ensinada por diplomado em Letras, e assim o é com tantos quantos forem os conteúdos curriculares. A generalidade da formação do professor que milita nos anos iniciais do ensino fundamental tem fundamento na legislação em vigor, fazendo parte de longa tradição que se acumula por várias gerações.(CNE, Parecer 16/2001, p.2)

O documento destaca a tradição desta medida, citando ato legal do Imperador D. Pedro I, de 15 de outubro de 1827, primeiro Estatuto do Magistério, onde já constava a atuação multidisciplinar do professor das primeiras letras. Entretanto, declara ser pertinente a atuação de profissionais especializados nos quatro primeiros anos do ensino fundamental, mas que os professores de atuação multidisciplinar não podem ser impedidos de realizar essas atividades e em especial as preconizadas na Proposta Pedagógica da Escola, dado que se encontram em sua esfera de obrigações.

Com isto o parecer citado defende a presença de um único professor nos anos iniciais, mas refere que não pode ser descartada a possibilidade da presença de professor especializado.

Por outro lado, sugere que

\begin{abstract}
Associações profissionais de classe, de pais e professores, os órgãos do poder executivo em todos os níveis etc. deveriam envidar esforços para que os professores tivessem condições objetivas de aprimorar seu desempenho profissional em todos os componentes curriculares. Cursos de formação continuada, inclusive para a prática de educação física pelas crianças da educação infantil e dos primeiros anos do ensino fundamental, são formas eficazes de caminhar em direção a práticas satisfatórias de educação física nas escolas. (idem p.3)
\end{abstract}

Com esta sugestão fica explicitada a intenção de buscar formas de aprimoramento dos professores dos anos iniciais para que possam desenvolver, com maior qualificação, 
uma docência multidisciplinar, ao encontro das ideias de Fraga (2005) quando sugere a presença do professor especializado sob forma de assessoria.

Também o Parecer CNE/CB n 11/2010, que fixa as Diretrizes Curriculares Nacionais para o Ensino Fundamental de 9 (nove) anos, no seu artigo 31 refere:

Do $1^{\circ}$ ao $5^{\circ}$ ano do Ensino Fundamental, os componentes curriculares Educação Física e Artes poderão estar a cargo do professor de referência da turma, aquele com o qual os alunos permanecem a maior parte do período escolar, ou de professores licenciados nos respectivos componentes.

Destacamos que o texto das Diretrizes Curriculares Nacionais coloca que Educação Física e Educação Artística poderão ser desenvolvidos pelo professor regente da turma ou professor especialista. Observamos portanto, que os dois documentos mencionados, oriundos do Ministério da Educação, não são contra a presença do professor especialista tanto na área da Educação Física como de Artes, nos anos iniciais do ensino fundamental.

Dirigindo nossa análise para a unidocência no Rio Grande do Sul onde essa organização curricular, além da dimensão pedagógica passa a se constituir numa gratificação salarial, retomamos uma investigação efetivada por Fonseca $(2006)^{3}$, sobre os caminhos percorridos pelos professores até a promulgação da Lei que transformou a unidocência em gratificação salarial.

\section{Unidocência na Cultura Docente Gaúcha}

A Lei n 8.747 de 1988, dispõe sobre o quadro de carreira, o quadro em extinção e as gratificações do magistério. $\mathrm{O}$ artigo $3^{\circ}$ da referida lei, determina que no artigo 70 da lei $\mathrm{n}^{\circ}$ 6.672, de 22 de abril de 1974 deve ser incluída a redação que define o pagamento de gratificação em regência de classes unidocentes no currículo por atividades. Tal gratificação corresponde a $50 \%$ do vencimento básico do quadro de carreira do magistério público estadual.

É importante destacar que a década de 1980 foi marcada por uma série de negociações salariais entre o governo e o magistério, que culminou, em 1987, com uma das maiores greves já deflagrada pelo magistério gaúcho, com duração de 96 dias. Os professores estavam reivindicando o cumprimento da lei 8026/1985, aprovada pelo governador Jair

${ }^{3}$ Trabalho de Conclusão de Curso realizado pela acadêmica Lísia Grosso da Fonseca, do curso de Licenciatura em Educação Física na ESEF -UFRGS sob a orientação do Prof. Dr. Alex Branco Fraga, intitulado "Significados das aulas de educação física para professoras unidocentes", em 2006. 
Soares (1983 - 1986), que determinava 2,5 salários mínimos, como salário base da categoria e que seu sucessor, Pedro Simon, (1987 - 1990) negara-se a cumprir. Entretanto, mesmo com o longo tempo de paralisação e as mais diversificadas formas de mobilização, o magistério não conquistou a manutenção dos 2,5 salários mínimos, pois foi arguida a inconstitucionalidade da Lei 8026/1985 (CPERS, 2006).

Novos impasses e reivindicações se sucederam até que o governo do estado apresentou uma proposta que, apesar de não contemplar os 2,5 salários previstos, estabelecia um índice de $96 \%$ de aumento parcelado em $70 \%$ em outubro e $26 \%$ em dezembro. Além dessa oferta salarial, foram adicionadas algumas vantagens funcionais e a gratificação por unidocência, através da Lei 8.747 de 21 de novembro de 1988.

Neste contexto, Oliveira(1988) explica que o governo propôs a gratificação de unidocência como forma de reduzir a diferença entre o salário dos professores com formação de nível médio e o daqueles que possuem licenciatura plena, respectivamente os níveis 1 e 5 do plano de carreira ${ }^{4}$, como uma alternativa também de resgatar os professores para dentro das salas de aula. Uma concessão similar à que temos hoje, com o pagamento do piso para aqueles professores que não o atingiam. Mais um mecanismo que, no atual momento pretende satisfazer minimamente uma prerrogativa legal, mas não contempla a valorização do magistério gaúcho, através de uma efetiva recuperação salarial.

Cabe lembrar que na época, diante da discrepância entre o baixo salário dos professores denível médio e a grande responsabilidade do trabalho com crianças no início da escolaridade, havia um número significativo de professores em desvio de função, ou seja, professores desenvolvendo atividades fora de sala de aula, como secretaria, biblioteca, merenda el ou outras funções para as quais não havia profissionais habilitados em exercício. Uma situação irregular, mas que de certa forma "acomodava" ambas as partes: os professores, diante dos baixos salários preferiam exercer atividades fora da sala de aula e o governo, por sua vez, se eximia de contratar profissionais para funções administrativas complementares ao trabalho docente. Com a concretização desta proposta, a unidocência no Rio Grande do Sul ganha outra conotação: gratificação salarial.

\footnotetext{
${ }^{4}$ A Lei 6.672/1974, do Estatuto e Plano de Carreira do Magistério Público do Rio Grande do Sul estabelece direitos, vantagens, deveres, responsabilidades e a estrutura da carreira que se organiza em seis classes, cada uma compreendendo seis níveis de habilitação. As classes constituem a linha de promoção por antiguidade e merecimento, identificadas pelas letras A,B,C,D,E e $\mathrm{F}$ e os níveis designados pelos números 1,2,3,4,5,e 6 constituem a linha de habilitação.
} 
Fonseca (2006) destaca que, desde 1988, com a promulgação da lei que regulamenta a unidocência, prevalece entre os professores a ideia de que a gratificação da unidocência pode ser ameaçada em função da presença de especialistas de determinadas áreas e que tal ideia não encontra respaldo no documento "Instruções para operacionalização da lei Unidoc/88", elaborado pela Secretaria de Educação do Estado do Rio Grande do Sul que complementam a referida legislação (RIO GRANDE DO SUL, 1988).

Unidocência e professores especializados - o trabalho de professores especializados (ed. física, ed. artística, línguas e outros) não descaracteriza a unidocência, que só será desconsiderada se o currículo já estiver estruturado por áreas (RIO GRANDE DO SUL,1988, p.3, grifos nossos).

Tal recomendação chama nossa atenção, pois neste documento fica claro que a lei não se refere à prática pedagógica unidocente, e sim à organização curricular, o que permite concluir que professores especializados podem atuar juntamente com os unidocentes sem comprometer o direito à gratificação, quando se tratar do currículo por atividades, ou se usarmos a denominação atual, quando se tratar dos anos iniciais do Ensino Fundamental.

É muito provável que este documento não seja de conhecimento dos professores unidocentes, bem como de professores especializados em exercício nas escolas de Educação Básica.

$\mathrm{Na}$ esteira das questões pedagógicas e salariais que ao longo dos anos tem implicado na questão da unidocência em relação à Educação Física, a pesquisa que realizamos se propôs a retomar o debate de questões que, no nosso entendimento, necessitam continuar em discussão.

\section{Análise e Discussão dos Dados}

Participaram deste estudo quatro professoras unidocentes, com formação em Pedagogia (três também possuem Habilitação Magistério), e dois professores formados em Educação Física que ministram aulas para os anos finais. A análise das informações foi realizada através do procedimento de análise de conteúdo, considerada como um conjunto de técnicas de análise de comunicações, tendo em vista a realização de inferências que possibilitam a passagem da descrição à interpretação. (BARDIN,1979) Nesta perspectiva, procedeu-se a análise das informações coletadas, organizadas em duas categorias, as 
quais emergiram do conteúdo das respostas: orientações para a docência da Educação Física e caracterização da prática pedagógica da Educação Física nos anos iniciais.

\section{Orientações para a docência da Educação Física}

As professoras unidocentes, ao serem questionadas sobre orientações por parte da secretaria de estado ou ministério da educação em relação à Educação Física nos anos iniciais, indicaram que não há, efetivamente, nenhuma política de formação e acompanhamento para essa especificidade do trabalho. Demonstraram não conhecer a proposta de Educação Física para os anos iniciais divulgada nos PCNs. Entretanto, mencionam que há orientações por parte da escola. De acordo com a fala das professoras: a orientação que a gente tem é pela escola , na verdade, [...]na EFi a gente trabalha mais com atividades de recreação. (AR)

Ao comentarem sobre sua formação para a docência da educação física, as professoras fazem referência às aprendizagens desenvolvidas na habilitação Magistério:

Eu utilizo tudo aquilo que eu aprendi no magistério. Brincadeiras, cantigas de roda, sabe? Brincadeiras que envolvam a psicomotricidade deles, movimento. Trabalho limites, tudo o que eu aprendi no magistério eu trago como estímulo, para eles não terem só o pensamento: na EFi a gente vai jogar futebol. [...] o magistério que me deu um norte. (AR)

Por outro lado, chama atenção a reduzida formação para o trabalho com o componente curricular Educação Física no curso de graduação das professoras ${ }^{5}$ participantes:

Eu fiz uma disciplina de Psicomotricidade, na faculdade, em que a professora fez brincadeiras com a gente... entregou aquela folha de sugestões com o que trabalhar na EFi com eles ... .[..] (AR)

Parece-nos, portanto, que estamos diante de um contexto onde as professoras unidocentes, em sua formação inicial, tiveram oportunidades restritas de reflexão sobre a especificidade da Educação Física, bem como sobre a importância da prática dos elementos da cultura corporal nos anos inicias do ensino fundamental.

\footnotetext{
${ }^{5}$ Devido à relevância deste dado, a temática referente aos currículos dos Cursos de Pedagogia será objeto de aprofundamento em outro artigo.
} 
Caracterização da prática pedagógica da Ed. Física nos anos iniciais

O diálogo com a coordenação pedagógica esclareceu a organização da prática da educação física nos anos iniciais da escola: tendo em vista que as professoras sentem-se pouco preparadas para realizar tais aulas é solicitado que as mesmas ministrem atividades de recreação em dois dias da semana. Uma das coordenadoras elaborou um polígrafo de atividades lúdicas com base em seus materiais da Habilitação Magistério e de pesquisa por ela realizada na internet e distribuiu às professoras com o intuito de motivá-las para o desenvolvimento de atividades recreativas.

Osentimento de despreparo por parte de professoras unidocentes para o desenvolvimento das aulas de educação física já foi discutido em outros estudos (Darido, 2001; Ayoub 2001 e 2005; Fonseca, 2006). Parece-nos que estamos distante de alterar este cenário uma vez que, conforme já explicitamos na categoria de análise anterior, as professoras participantes indicam a ausência de ações formativas oriundas do poder público relacionadas ao trabalho com a Educação Física. Nessa perspectiva, o que dizem as professoras sobre a prática da Educação Física nos anos iniciais nessa escola:

[...] eles querem o futebol, o que a gente faz? Joga um futebol. Quando tu queres fazer uma atividade dirigida, tem uma polêmica, porque eles já estão direcionados para o futebol. Mas eles gostam de brincar, ai o que q gente faz: o "ovo choco", eles gostam de brincar, pular corda, o "caçador" [...]mas o que mais chama a atenção é o futebol [...] (MR)

[...] eles têm dois dias de recreação no pátio. Algumas professoras [...] fazem aquele momento com atividades de recreação [...] $E$ a gente também vê muita professora que no horário da recreação deixa aluno livre no pátio. (SI)

A propósito dessa questão, na opinião dos dois professores de Educação Física que atuam na escola a partir do $6^{\circ}$. ano do Ensino Fundamental, as aulas de educação física ministradas pelas professoras unidocentes não propiciam o desenvolvimento das habilidades motoras, causando dificuldades para o desenvolvimento dos conteúdos da área nos anos finais:

[...] o que eu vejo é uma recreação [...]quando as crianças chegam no atual sexto ano ou antiga quinta série, chegam com medos, medo da bola, não conseguem manipular o material corretamente. São algumas habilidades básicas que já deveriam ter sido desenvolvidas.. A gente percebe que são deficiências não do aluno e sim do trabalho desenvolvido [...] (P1) 


\section{Encaminhando Algumas Considerações}

A retomada da questão da Educação Física nos anos iniciais do Ensino Fundamental nos permite recolocar a unidocência como foco de análise porque entendemos que a discussão sobre esse tema não pode ser considerada esgotada. A realização do estudo nos permitiu conhecer e aprofundar questões relacionadas à realidade das professoras unidocentes que atuam nos anos iniciais do ensino fundamental com relação à prática pedagógica da educação física, bem como o contexto político que serviram de sustentação e cenário para os movimentos que culminaram com a normatização da unidocência no RS.

Nessa caminhada, constatamos que a par dos aspectos psicopedagógicos que justificam a presença de um único professor nos anos iniciais, a gratificação salarial veio dar um sentido político-legislativo fazendo com que as professoras acreditassem que por receber a gratificação deveriam ser as "únicas" docentes a trabalhar com as crianças. A existência de instruções para operacionalização da lei da gratificação da unidocência apontando que pode haver a presença de professores especializados sem prejuízo da gratificação, bem como as resoluções e pareceres das instâncias federal e estadual, não apresentam determinações impeditivas da presença de professor especializado em Educação Física nos anos iniciais do Ensino Fundamental.

Por fim queremos reafirmar as razões que nos levaram a retomar o debate sobre o tema. Sabemos que a criança aprende de forma globalizada. Concordamos que a superação da ideia de que a criança não é um adulto em miniatura promoveu mudanças significativas nos modos de pensar a educação escolar (e a não escolar também), orientando organizações curriculares e práticas pedagógicas com o objetivo de qualificar o processo de ensino aprendizagem.

Entretanto, em se tratando do componente curricular Educação Física, toda a argumentação pedagógica e legislativa que sustenta a presença de único professor nos anos iniciais parece não ser mais suficiente para justificar a unidocência na forma como é praticada no Rio Grande do Sul, onde, parafraseando Cruz e Neto (2012), temos nos documentos uma unidocência ideal e, na prática, uma outra unidocência, a real, que passa a merecer questionamento diante das complexas situações que atravessam o exercício da docência na atualidade. 
Nossa presença nos últimos anos, como supervisoras de estágio em escolas públicas estaduais, e os resultados desta pesquisa sugerem que quase nada mudou. Portanto, o que nos parece imperativo neste momento é perguntar:

- como manter encoberta uma situação educacional que se arrasta ao longo das últimas décadas com evidências de esgotamento?

- como pensar a presença do componente curricular Educação Física nos anos iniciais, garantindo e qualificando o direito a esse conhecimento de forma condizente com a sua relevância na formação da criança?

- como superar uma realidade que no plano discursivo parece responder e contemplar com propriedade e profunda argumentação uma situação que não se legitima no dia a dia das escolas?

\section{Referências:}

AGUAYO, A.M. Didática da Escola Nova. São Paulo:Companhia Editora Nacional, 1947.

AYOUB, E. Reflexões sobre a educação física na educação infantil. Revista Paulista de Ed Física, São Paulo, supl.4, p.53-60, 2001.

Memórias da educação física escolar. In: XIV CONGRESSO BRASILEIRO DE CIENNCIAS DO ESPORTE/I CONGRESSO INTERNACIONAL DE CIÊNCIAS DO ESPORTE. Porto Alegre, 2005.

BARBOSA, Maria Carmen Silveira. Trabalhando com projetos na Educação Infantil,. In:XAVIER, Maria Luiza e DALLAZEN, Maria Izabel. Planejamento em destaque: análises menos convencionais. Porto Alegre: Mediação, 2000.

BARDIN, L. Análise de conteúdo. Lisboa: Ed. 70, 1979.

BRASIL, Secretaria de Educação Fundamental. Parâmetros Curriculares Nacionais: Educação Física. Brasília: MEC/SEF, 1997.

BRASIL, Ministério da Educação. Lei N. 9394 de 20 de dezembro de 1996. Estabelece as Diretrizes e Bases da Educação Nacional. Disponível em <http://www.planalto.gov.br/ ccivil_03/Leis/L9394.htm>. Acesso em 20 de maio de 2013.

BRASIL, Ministério da Educação, Conselho Federal de Educação. Parecer N. 853, de 12 de novembro de 1971. Núcleo-comum para os currículo do ensino de $1^{\circ}$. e $2^{\circ}$. Graus. In 
Documenta n. 132, Rio de janeiro, nov. 1971.

BRASIL, Ministério da Educação, Conselho Nacional de Educação. Parecer N. 16 de 03 de julho de 2001. Consulta quanto à obrigatoriedade da Educação Física como componente curricular da Educação Básica e sobre a grade curricular do curso de Educação Física da rede pública de ensino. Disponível em < http://portal.mec.gov.br/cne/arquivos/pdf/ pceb16_01.pdf>. Acesso em 20 de maio de 2013.

BRASIL, Ministério da Educação, Conselho Nacional de Educação. Parecer 11 de 07 de julho de 2010. Diretrizes Curriculares Nacionais para o Ensino Fundamental de nove anos. Disponível em

<http://portal.mec.gov.br/index.php?option=com_content\&view=article\&id=15074\&ltem id=866> . Acesso em 20 de maio de 2013.

CONTREIRA, C. B. e KRUG, H. N. Educação Física nas séries iniciais do ensino fundamental: um estudo de caso com professores unidocentes. Revista Digital. Buenos Aires, Año 15, № 150, noviembre/2010. Disponível em: http://www.efdeportes.com. Acesso em $10 / 06 / 2012$

CPERS - Sindicato. Quem somos. Disponível em: http://www.cpers.com.br/portal2/ historia/4-historico_das_greves.pdf. Acesso em: Outubro. 2006.

CRUZ, S. P. da S e NETO, J. B. A polivalência no contexto da docência nos anos iniciais da escolarização básica: refletindo sobre experiências de pesquisas. Revista Brasileira de Educação. Vol.17 nº 50 maio-agosto 2012.

DARIDO, S. C. Educação Física de $1^{\mathrm{a}}$ a $4^{\mathrm{a}}$ série quadro atual e as implicações para a formação profissional em Educação Física. Revista Paulista de Ed. Física, São Paulo: n. 4, 2001.

FONSECA, L. G. da. Significados das aulas de educação física para professoras unidocentes, 2006. TCC (Licenciatura em Educação Física) ESEF,UFRGS, Porto Alegre, 2006.

FRAGA, A.F. Educação Física nos primeiros anos do ensino fundamental brasileiro. Revista Digital. Buenos Aires, Año 10, № 90, Noviembre/2005. Disponível em: http://www. efdeportes.com. Acesso em 10/06/2012

MELO. J. P. Perspectivas da Educação Física Escolar: reflexão sobre a Educação Física 
como componente curricular. Revista Brasileira de Ed. Física e Esporte. São Paulo, v.20, p.188-90, 2006.

MENSCH, D. I. e SCHWENGBER, M. S. Jogar bola, brincar na pracinha e plantar bananeira": representações sociais de crianças sobre a educação física . Motrivivência Ano XXI, Nº 32/33, P. 280-295 Jun-Dez./2009.

MEURER, Ane Carine; PEREIRA, Érico Felden. Epistemologia da prática pedagógica na Educação Física nas séries iniciais do ensino fundamental. Revista Digital. Buenos Aires, n.84, Maio, 2005. Disponível em: http://www.efdeportes.com. Acesso em 10/06/2012

OLIVEIRA, Therezinha Ribeiro. Princípios de aprendizagem e metodologias do ensino de $1^{\circ} \mathrm{grau}$. Porto Alegre: SAGRA, 1988.

RIO GRANDE DO SUL, Lei N. 6672 de 22 de abril de 1974. Estabelece Estatuto e Plano de Carreira do Magistério. Porto Alegre, 1974. Disponível em <http://www.educacao. rs.gov.br/pse/html/magist_estatuto.jsp>. Acesso em: 10 de março de 2013.

RIOGRANDEDOSUL, Lein ${ }^{\circ} 8.747$ de 21 de novembro de/1988. Dispõe sobre o Quadro de Carreira, o Quadro em Extinção e as gratificações do Magistério Estadual. Porto Alegre, 1988. Disponível em : < http://www.al.rs.gov.br/legislativo/Legisla\%C3\%A7\%C3\%A3oEstadual. aspx>. Acesso em 10 de março de 2013.

RIO GRANDE DO SUL. Secretaria de educação e cultura. Instruções para operacionalização da lei da unidocência. 1988. Documento fornecido pelo CPERS.

SAYÃO, M.C. Educação Física na educação infantil: riscos,conflitos e controvérsias. Motrivivência, v.11, n013, p. 221-38, 19

SILVA, M. S. da e KRUG, H. N. A formação inicial de professores de educação físicae de pedagogia: um olhar sobre a preparação para a atuação nos anos iniciais do ensino fundamental. Revista Digital. Buenos Aires, Año 13, № 123. Disponível em: http://www. efdeportes.com. Acesso em 10/03/2013

SCHÜTZ, M. B. A formação de normalistas para o trato da Educação Física nas séries iniciais do Ensino Fundamental: um estudo de caso na rede estadual de PortoAlegre.2011.. TCC. ESEF/UFRGS, Porto Alegre, 2011. 


\title{
PHYSICAL EDUCATION IN THE EARLY YEARS OF BASIC EDUCATION: THE QUESTION OF UNIDOCÊNCIA
}

\begin{abstract}
This article is a part of the research entitled "Teacher education policy: what are the implications in pedagogical practice of physical education in state public schools?" and it aims to reflect on the physical education in early years focusing in one teacher for all the subjects and salarial compensation. It is a qualitative research, conducted through document analysis and semi-structured interviews with six teachers. Despite the legislative and pedagogical reasoning that justifies one teacher the information analysis indicates that, with regard to physical education, practice needs to be revised.
\end{abstract}

Key words: Pedagogical practice. Physical Education. One-teacher school practice.

\section{EDUCACIÓN FÍSICA EN LOS PRIMEROS AÑOS DE EDUCACIÓN BÁSICA: LA CUESTIÓN DE UNIDOCÊNCIA}

RESUMEN: Este artículo es parte de una investigación titulada "Políticas para la formación del profesorado: ¿qué implicaciones para la práctica pedagógica de la educación física en las escuelas públicas del estado?" y tiene como objetivo reflexionar sobre la educación física en los primeros años centrando en la unidocência como práctica pedagógica y gratificación salario. Se trata de una investigación cualitativa, llevada a cabo a través del análisis de documentos y entrevistas semi-estructuradas con seis profesores. A pesar del razonamiento legislativo y pedagógico que justifique el unidocência, análisis de las información indica que, con respecto a la educación física, la práctica tiene que ser revisada .

Palabras clave: Práctica pedagógica. Educación Física. Unidocência 